been lost. Notwithstanding the absence of this conclusive proof, northern scholars are inclined to accept the later transcript as a bona fide version of the original before the loss of its missing parts, and if this assumption can be maintained, we have evidence that the Northmen advanced four days' journey north of $76^{\circ}$. The object of the expedition, we are informed, was to discover what lands and people were to be found north of the Christian Station at Garde, and whether the much dreaded Skröllinger or native Esquimaux occupied those unknown regions in any formidable numbers. The seamen, we are told, saw many islands on which there were traces of the presence of these people, but they were unable to land, owing to the number of bears which, together with numerous seals and whales, frequented the coasts. In reference to the high latitude said to bave been reached by these early explorers, and which is inferred from the description of the height of the sun on St. James's Day (July 25), it may be observed that a runic stone was found in 1824 in $72^{\circ} 55^{\prime}$ N. lat, about twenty miles north-weit of Upernivik, the northernmost existing Danish station. The inscription, which records that three men, whose names are given, erected the stone as a landmark, concludes with six runic characters, which have been variously interpreted to indicate the years I I35 and 1235 .

From his scientific expedition to Anatolia, Syria, Egypt, India, Indo-China, China, and Japan during the years $1880-83$, Dr. Emil Riebeck has lately returned to Europe Iaden with ethnological and archæological treasures of all sorts. This splendid collection, on which the enterprising explorer has expended no less than $30,000 \%$., has during the past few months formed a chief attraction to naturalists in Berlin, where it has been on exhibition at the Kunstgewerbe Museum. Here the available space was not sufficient to allow of a thoroughly systematic arrangement of the objects, which however have been roughly disposed in three main geographical groups:- - (I) Western Asia and Africa; (2) India and Further India ; (3) East Acia (China and Japan). Some idea of the immense variety of articles here brought together may be had from the detailed catalogue of Dr. Riebeclk's "Asiatic Collection," recently issued by Messrs. Weidmann of Berlin. From Palestine and Syria we have object of every description; while the articles from Somaliland, which are very numerous, illustrate almost every phase of the social life of the little known inhabitants of that region. Several specimens are shown of the masks used in Ceylon at the "devi dances" performed during illness. The masks represent divinitie; of the. Hindu mythology, rakshasas or demons, nāgakanyā or snake masks, lions, tigers, crocodiles, negroes, Mussulmans, Malays, \&c. India is largely represented. From Burmah, where the Irrawadi was ascended as far as Bhamo, were brought man costly articles, such as royal coronets and dresses, alabaster and gilt wooden statuettes of Buddha, masks of strolling minstrels and players, amber rosaries, richly carved consols, lacquer ware, ornamental drinking vessels, writing materials, \&c. A visit to Bangkok yielded models of Siamese floating houses, fishing gear, agricultural and industrial implements, \&c. Amongst the most characteristic objects from China are brightly painted clay models of popular types, bronze vases, chased, inlaid in silver, and studded with gems ; shallow dishes of "imperial bronze" (yellow picked out in red), silver teapots, artistic articles in jade, rock crystal, and marble, \&c. The rich and varied Japanese collection comprises specimens of all the most characteristic productions of the country, especially Satsuma porcelain and other ceramic ware, illustrating the development of Japanese porcelain from the sixteenth to the nineteenth century. During the first part of his journey Dr. Riebeck was accompanied by Dr. Moock, who, after escaping from many perils amongst the Bedouin tribes in the Moabite country, was drowned in crossing the Jordan and now lies buried in Jericho. During the visit to Egypt he was attended as far as the Nubian frontier by Dr. Schweinfurth, who again accompanied him in March I881 to the south coast of Arabia and the Island of Socotra. During the rest of his wanderings throughout the Far East Dr. Riebeck had for his associates M. C. B. Rosset, who joined him in Germany, and Dr Mantei, whom he engaged in Egypt after the untimely death of Dr. Moock.

In the March part of Good Words Mr. Edward Whymper gives some particulars of his journeys in Greenland which have not been heretofore published; and states that he found the height of the interior in the latitude of Umenak (about $70^{\circ} 30^{\prime} \mathrm{N}$.) considerably exceeded ro,ooo feet. Mr. Whymper says that from the various mountains he has accended on the eastern side of Davis Straits he has had continuous views of the glaciercovered interior of Greenland between about $68^{\circ} 30^{\prime}$ and $71^{\circ} 15^{\prime}$ $\mathrm{N}$. lat., and that there is no break or depression within those limits, and that the country is everywhere so absolutely covered by snow and glacier that not a single rock or crag can be seen.

\section{ON THE PHENOMENA EXHIBITED BY DUSTY AIR IN THE NEIGHBOURHOOD OF} STRONGLY ILLUMINATED BODIES ${ }^{\perp}$

IN I87o Dr. Tyndall described the dark or dust-free plane which rises from a hot body in illuminated dusty air, and gave two explanations of the dust-freeness of this dark space. Another explanation was suggested by Dr. Frankland. In r88I Lord Rayleigh re-examined the phenomenon, and discovered that a cold body gave a similar down-streaming plane. $\mathrm{He}$ also suggested a totally different explanation. The writers discuss all these suggested explanations, and see reasons for rejecting them all. They have, moreover, observed that the dark plane rising from a hot body is only a prolongation of a well-defined dust-free coat of nearly uniform thickness under ordinary circumstances surrounding the body, and they point out that this dark coat is the thing really requiring explanation, the dark plane being merely due to the up-carrying of portions of this coat by convection currents.

The preliminary experiments were described in a letter to NATURE Iast July (vol. xxviii. p. 297).

The dark coat is found to increase in thickness with the temperature of the body, becoming very thick at high temperatures, say $1000^{\circ} \mathrm{C}$., but being narrow for temperatures only a few degrees above the air. When the temperature of the body is the same as that of the air surrounding it, the dust-free coat is either nonexistent or exceedingly thin. The thickening of the coat by a rise of temperature is interfered with by convection-currents, which sweep the outer portions off more rapidly than they can be renewed, and so make the coat thinner than it otherwise would be. By means of a blast of air the coat can be almost wholly or entirely blown away ; but convection-currents are never able to sweep it off, for the same cause which increases the convection-currents also broadens and assists the formation of the coat. The coat can be seen on round rods of all materials, on flat plates, both horizontal and vertical, on hollow and irregularly shaped pieces, and in general on every substance whatever. Nevertheless the behaviour of certain bodies is peculiar, and is detailed in the paper; such bodies, for instance, as a stick of phosphorus, which itself gives off smoke, a volatile solid like camphor, moistened solids like soaked carb on, liquids like sulphuric acid water and ether, and thin films of glass or mica. Other substances examined are: copper, iron, zinc, electric-light carbon, charcoal, glass, mica, selenite, selenium, Iceland spar, tourmaline, potash, rock salt, bismuth, silver, chalk, and all kinds of paper. In every case the method of examination was as follows :-A glass box was mounted in front of the nozzle of an electric lantern, and the body to be examined was supported in any convenient manner, so as to be about the middle of the box, and to be well illuminated. Smoke was introduced, the lamp turned on, and the effect examined by looking along the length of the body at right angles to the light. Sometimes a microscope was used, but it was not necessary except for measurements. A hand lens is useful. For smoke, tobacco was the most common, but am. monic chloride was used when a distinctly volatile smoke was desired, and magnesic oxide whenever a non-volatile and incombustible smoke was wanted. Any kind of smoke serves equally well. Hydrogen and carbonic acid and other gases have been used as well as air : in hydrogen the coat is much thicker, in carbonic acid a little thinner, than in air. The effect of pressure on the dark coat was examined, and it is found that the coat broadens as the pressure diminishes. An increase in pressure of $4 \frac{1}{2}$ atmospheres renders the coat very thin and sharp, and at the same time causes the convection-currents to be sluggish.

The writers considered that it would be very instructive to examine whether a dark coat and plane could be observed when a warm body was immersed in a dusty liquid; and they accordingly devoted a good deal of attention to this point. After failures with mastic and other substances, they succeeded in observing a very thin, dark coat on the surface of an iron wire immersed in water

I Abstract of a paper by Oliver J. Lodge and J. W. Clark, read at the Physical Society, February 9 
holding rouge in suspension, with a dark plane rising from it. It is not always easy to obtain the dark coat in liquids, however, and its thickness is enormously less than it is in air. Moreover, the results are less definite and satisfactory. In gases the thickness of the coat may be anything below the eighth of an inch, according to the circumstances of the case, but its commonest width is more comparable with the hundredth of an inch. On a carbon rod in an electric beam the coat js about half a millimetre thick, no other heat being applied. Glass shows a perfect coat and dark plane, but for some reason or other very thin films of glass ('0003 inch thick) behave differently, and it is sometimes by no means easy to see any coat at all. It may be that such thin films are unable to absorb enough radiation, or it may be that the cause is more deeply seated. It can bardly be that they give off their heat too rapidly, because the convection-currents set up by them are very sluggish. It is pretty certain that they fail to absorb radiation; for a plate of rock-salt in a perfectly dry atmosphere behaves in the same way. In ordinary air, a lump of rock-salt is able to absorb sufficient radiation to give a satisfactory dark plane. The behaviour of thin films is under further investigation. Covered with lampblack they act perfectly well. Incidentally it has been noticed that films of freshly-blown glass adhere together though cold, giving the black spot; but that when films are a day or two old they refuse to adhere, doubtless because of the condensed air-sheets with which they have coated themselves. The slow formation of these condensed sheets, as studied recently by Bunsen (Wied. Ann. February 1884) is of great interest.

The effect of electrifying rods from which a dark plane is streaming is not marked except when the potential is bigh ; 100 volts or so produce a little effect, positive potential broadening the coat, negative potential narrowing it. As soon as a bnush discharge occurs, the effects are violent and the air is rapidly cleared of smoke, the particles being deposited on all the surfaces near. Various electrical phenomena can be conveniently examined by means of smoky air ard a strong beam of light. Thus a flake of mica, on being examined for its coat one day, showed a curious phenomenon. The dust aggregated on its surface in little bushes or trees, and its edge became fringed with long aggregations of dust particles. Our first thought was that mica was photo-electric, but we now think that it had been perhaps electrified by casual pressure. This also is still under investigation. Tourmaline shows all its pyro-electric properties exceedingly well by being simply illuminated in dus:y air. If mica be written on with a blunt point, a sheet of paper intervening, the writing becomes manifest when it is exposed to dust. We find, however, that a brass plate is capable of acting in a similar way, and we are not prepared to be content with a mere electrical explanation. We are probably here dealing with phenomena allied to those known as Hauchbilder, which are supposed to be connected with the condensed air-sheet on the surface of solids; though their explanation may also be associated with vapour-condensing nuclei on solid surfaces. The phenomena connected with the settling of dust on surfaces by gravitation have also been investigated, and it is found that so long as a body is warmer than the air it keeps itself free from dust; except that just at the top, where the air is stagnant, the excess of tem. perature being only small, a large particle or two may drop on. The dust-free coat is not an absolute barrier to dust: it marks the region into which dust is not carried by convection-currents; but other causes may drive dust into this region. Thus it may be blown into it either from outside or through a hole in the rod itself if it be hollow; or the rod may give off smoke, or the dust may, as stated, occasionally drop into the dark region by common gravitation. The persistence of the dust-free plane at a distance from the body which produced it is dependent on the motion of the dust particles with the air stream-lines; whatever drives du't across stream-lines interferes with and tends to obliterate detached dust-free regions. All dark streaks in smoky air are commonly the wiped-off coats of bodies.

We have been led to a fairly complete explanation of the whole phenomenon, and thungh it is impossible to attribute every case of dust-freeness to one single well-defined cause, we see reason to believe that the main causes in ordinary operation are two, viz. :-

\section{Molecular bombardment.}

2. Gravitative settling.

We were long under the impression that the sheets or films of condensed gases which are known to exist on the surface of all bodies were connected with the dark coats, and had some share in their production; and this view was pressed home by an observation of the surface of warm water in dusty air. The evaporation of the water drives back the dust and keeps a clear space of some thickness above the water; and if the water be linearly heated by a plarinum wire stretched just beneath its surface and warmed by a current, the dark coat streams upward in a fine and well-defined dust-free plane. The up-streaming of the portion above the wire causes the remainder to become thinner, until there is an evident equilibrium between the rate at which the evaporation reproduces the dark coat and the rate at which the convection current carries it off. That the dust is kept off a solid, say a warm copper wire, by an evaporation and continued renewal of its condensed air-sheet, we think decirledly improbable, but we are convinced that the dust particles are driven away from the solid by some form of molecular bombardment, possibly such as goes on from the vanes of a ( rookes' radiometer. There is, however, a very great difference between the two phenomena; the Crookesian layer is supposed to correspond with the mean free path, and this is enormously less than the thickness of a dust-free coat. A possible suggestion is that the dust-free coat represents something more like the extreme free path of the molecules, the dust particles being so easily moved that they are driven away by the blow's of even a few molecules. A simpler and more satisfactory mode of pulting the matter is this. The temperature of the air near a warm solid decreases gradually as we recede from its surface. Consequently a dust particle in the neighbourhood of the solicl has warmer air on one side of it than on the other; in other words, it receives heavier and more numerous blows on one side than on the other, and accordingly is driven away from the warm body. Whenever the temperature of air is steadily dif ferent in successive layers, there the dust particles must get driven in the direction of decreasing temperature at a rate depending on the temperature slope. This is not complete, however, because the extra temperature really shows itself as a diminution of density, not as an increase of pressure. The explanation is further elaborated in the paper, which will appear in the Philosophical Magazine for April. The conduction of heat across the air near a hot body is itself an interesting problem. So also is the distribution of up-streaming velocities. The maximum velocity of convection occurs at some distance from the body, being often ditinctly outside the dust-free coat.

Some few cases of the dust-fiee coat and plane can hardly be explained in the manner now indicated. We point out, however, that gravitation is an effective cause certainly in operation, which of it:elf is competent to account for the formation of dust-free spaces when circumstances are favourable. Dust is always settling or falling downward relatively to the air in which it is. The velocity of relative fall depends on the size of the particle, on the density and viscosity of the gas, but not on the motion of the gas. Immediately below a solid body round which gentle currents are rising, there is a small region of nearly stagnant air; out of this dust slowly falls, leaving it free, and if then part of it is dragged round the body by the currents, it contributes to the dark coat and to the ascending dark plane. Underneath horizontal plates, also, this gravitation-settling of the dust assists and broadens the coat. But there is also a coat on the upper surface; and this coat gravitation, so far from producing, does its best to spoil. A few of the larger particles are in fact seen to fall occasionally through it on to the surface of the body, their weight being too great for the bombardment to sustain. In the case of a cold body the down-streaming currents deposit a good deal of dust on the upper surface of the body, and so that portion of air which has grazed the surface passes on dust-free. The tendency now is for the warmer air outside the dust to bombard it on to the cold surface. This goes on all over the upper half of the body, but over the lower half a coat is visible when the cold is not too great, but it is only fairly thick at the bottom of the body when it forms the base of the inverted dark plane. A smooth vertical surface of ice gives no dark coat, and the maximum velocity of the particles in the descending current is apparently little, if at all, distant from the actual surface. Finally the writers call attention to a paper just read at the Royal Society of Edin. burgh by Mr. John Aitken. They have only seen an abstract of this paper at present, but it appears that Mr. Aitken has been travelling over much of the same ground as they have, and that he has arrived on the whole at fairly the same conclusions. The abstract of Mr. Aitken's interesting paper was printed in NATURE of January 3I (p. 322). 